\title{
Intractable Back Pain After Coil Embolization of Giant Veno-Venous Collaterals in a Patient With Fontan Circulation
}

\author{
Seigo OKada, ${ }^{1}$ PhD, Masahiro Kamada, ${ }^{1}$ PhD, Naomi NaKagawa, ${ }^{1} \mathrm{PhD}$, \\ Yukiko Ishiguchi, ${ }^{1} \mathrm{MD}$, Yuji Moritoh, ${ }^{1} \mathrm{MD}$, Mayuko Shohi, ${ }^{1} \mathrm{MD}$, \\ Kengo Окамото, ${ }^{1} \mathrm{MD}$, Shunji Hasegawa, ${ }^{2} \mathrm{PhD}$, and Shouichi Ohga, ${ }^{2} \mathrm{PhD}$
}

\begin{abstract}
SUMMARY
Veno-venous collaterals are sometimes seen in patients after the Fontan procedure. A 28 -year-old female with tricuspid atresia who underwent the Fontan procedure had oxygen desaturation due to a giant veno-venous collateral. Coil embolization was performed for the collateral. After the procedure, she complained of severe back pain. Anti-inflammatory analgesics and steroids were not effective, although carbamazepine promptly relieved the intractable pain. Treatment-related pain after coil embolization for veno-venous collaterals in patients with Fontan physiology is quite rare, although cardiologists must recognize a critical condition to be differentiated from vascular occlusion. (Int Heart J 2017; 58: 298-301)
\end{abstract}

Key words: Cardiac catheterization, Complication, Neuropathic pain, Total cavopulmonary connection

$\mathrm{T}$ he complete caval-pulmonary repair of single ventricle lesions has created a whole new spectrum of systemic artery to pulmonary artery and systemic vein to pulmonary vein collaterals/fistulae. ${ }^{1)}$ These collaterals provide competition to the already precarious forward pulmonary blood flow, produce extra volume on the single ventricle, and/ or create a right to left shunt with systemic desaturation of the patient. ${ }^{1)}$ Therefore, when "Fontan" type patients undergo catheterization, cardiologists should check these lesions carefully and occlude if they exist. ${ }^{1,2)}$

Occlusion of vital structures/organs, embolization of unwanted areas, migration of devices, and hemolysis are wellknown complications of vascular occlusions. ${ }^{1)}$ To the best of our knowledge, there are no previous reports regarding the refractory pain associated with the procedures of coil embolization for veno-venous collaterals in patients who underwent the Fontan operation.

Here, we describe a 28-year-old female with Fontan physiology who developed intractable severe back pain after undergoing coil embolization for giant veno-venous collaterals. Carbamazepine successfully controlled the intractable pain although many other analgesic drugs failed to relieve it.

\section{Case Report}

A female patient with tricuspid atresia (type Ic) initially underwent banding of the pulmonary arterial trunk at 6 months of age. The second operation had not been carried out until she was 5 years old, when the total cavopulmonary connection (lateral tunnel) was completed. She received coil embolization of a veno-venous collateral from the innominate vein to the left atrium for the first time when she was 12 years old. At that time, her peripheral oxygen saturation was at around $90 \%$. She was referred to our hospital when she moved to our city at 26 years of age. Two years after the first visit to our hospital, a follow-up enhanced computed tomography (CT) revealed many veno-venous collaterals (Figure 1A). Her peripheral oxygen saturation was $86 \%$ under room air. Hence, she was admitted to our hospital for embolization of the collaterals. On admission, she was well and her vital signs were as follows; blood pressure 110/70 $\mathrm{mmHg}$; pulse rate $78 / \mathrm{min}$; body temperature $36.5^{\circ} \mathrm{C}$; and peripheral oxygen saturation $83-88 \%$. Complete blood counts showed leukocytes $5.4 \times 10^{9} / \mathrm{L}$, hemoglobin $17.4 \mathrm{~g} / \mathrm{dL}$, and platelets $156.0 \times 10^{9} / \mathrm{L}$. Blood chemistry values were as follows; aspartate transaminase, $25 \mathrm{IU} / \mathrm{L}$; alanine transaminase, $23 \mathrm{IU} / \mathrm{L}$; gamma-glutamyl transpeptidase, $77 \mathrm{IU} / \mathrm{L}$; total bilirubin, $1.0 \mathrm{mg} / \mathrm{dL}$; albumin, $4.8 \mathrm{~g} / \mathrm{dL}$, C-reactive protein (CRP) $0.04 \mathrm{mg} / \mathrm{dL}$, and N-terminal pro-Btype natriuretic peptide $300 \mathrm{pg} / \mathrm{mL}$. The cardiac catheterization findings were as follows; the ratio of total pulmonary blood flow to total systemic blood flow (Qp/Qs) 1.0; pulmonary vascular resistance 1.6 wood unit $\mathrm{m}^{2}$; mean pulmonary artery pressure $11 \mathrm{mmHg}$; and mean central venous pressure 12

From the ${ }^{1}$ Department of Pediatric Cardiology, Hiroshima City Hiroshima Citizens Hospital, Hiroshima and ${ }^{2}$ Department of Pediatrics, Yamaguchi University Graduate School of Medicine, Yamaguchi, Japan.

Address for correspondence: Seigo Okada, PhD, Department of Pediatric Cardiology, Hiroshima City Hiroshima Citizens Hospital, 7-33 Motomachi, Naka-ku, Hiroshima 730-8518, Japan. E-mail: sokada0901@gmail.com

Received for publication April 23, 2016. Revised and accepted August 11, 2016.

Released in advance online on J-STAGE March 21, 2017.

All rights reserved by the International Heart Journal Association. 

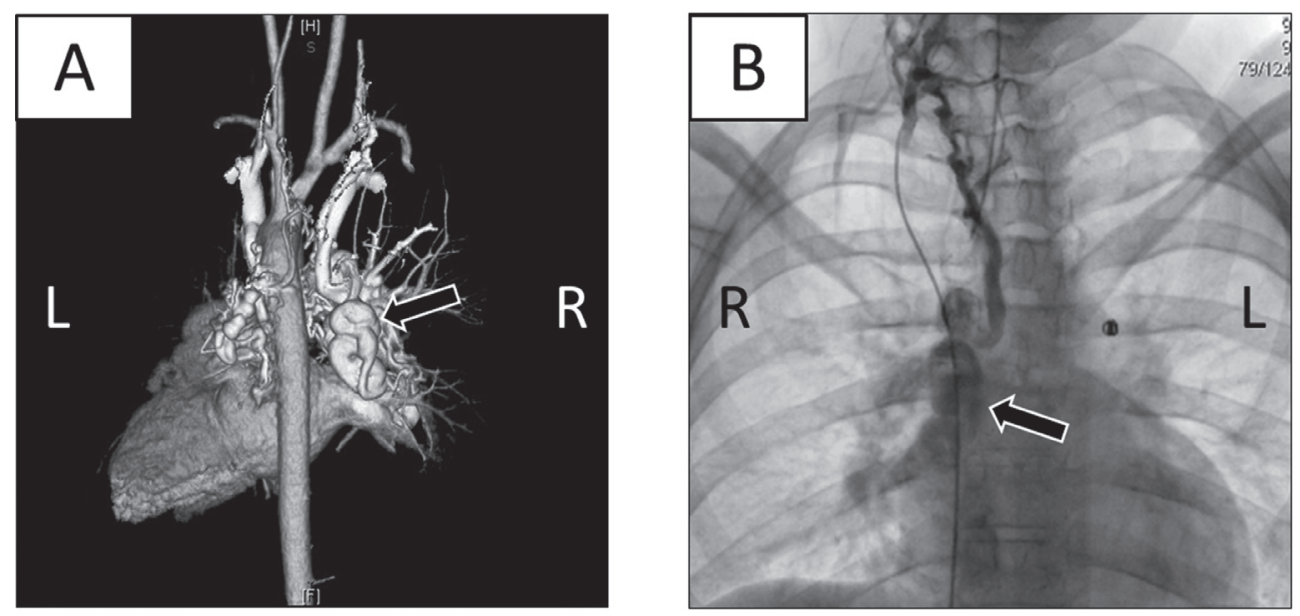

Figure 1. Veno-venous collaterals developed after the Fontan procedure in the present patient. Arrows indicate the giant collateral which underwent coil embolization. A: Three-dimensional computed tomography. B: Selective angiography of giant collateral. The blood flows from internal jugular vein to pulmonary veins.
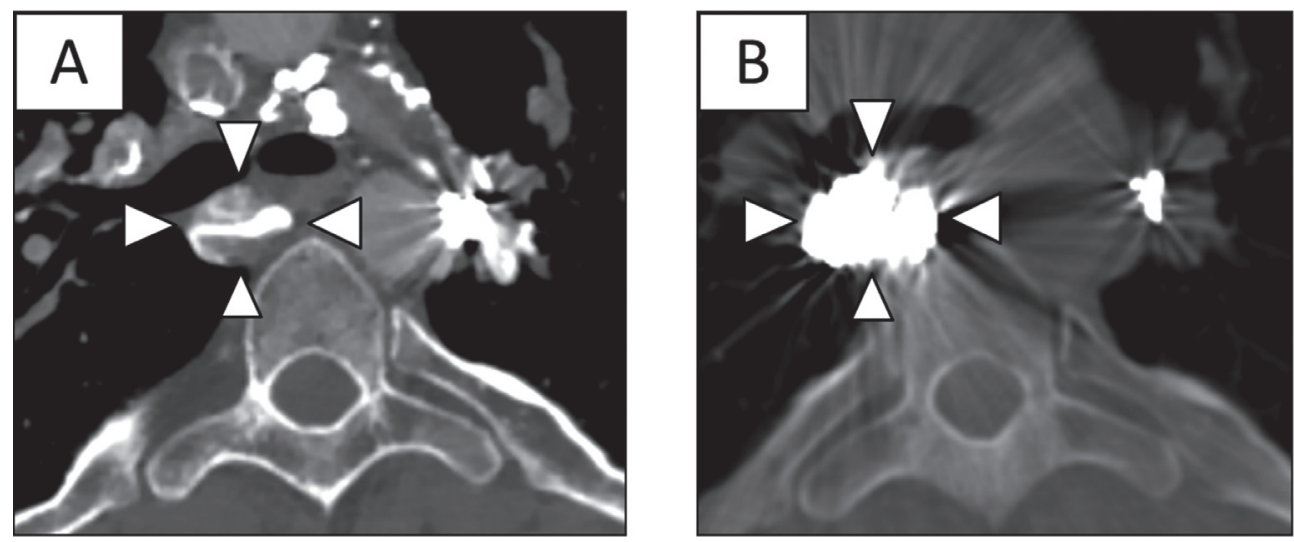

Figure 2. Computed tomography before $(\mathbf{A})$ and after $(\mathbf{B})$ coil embolization for giant collateral. Arrow heads indicate giant veno-venous collateral. Maximum diameter of the collateral increased from $19.4 \mathrm{~mm}(\mathbf{A})$ to $23.0 \mathrm{~mm}(\mathbf{B})$.

mmHg. Selective collateral angiography revealed giant venovenous collaterals from an internal jugular vein to pulmonary veins (Figure 1B). We performed coil embolization at the same region using a total of 18 coils (Target $\mathrm{XL}^{\circledR}$ Detachable Coils, Stryker Japan K.K., Osaka, Japan: $10 \mathrm{~mm} / 40 \mathrm{~cm}^{*} 1,12 \mathrm{~mm} / 45$ $\mathrm{cm}^{*} 2,14 \mathrm{~mm} / 50 \mathrm{~cm}^{*} 1,16 \mathrm{~mm} / 50 \mathrm{~cm}^{*} 1,18 \mathrm{~mm} / 50 \mathrm{~cm}^{*} 1,24$ $\mathrm{mm} / 50 \mathrm{~cm}^{*} 1$; AZUR ${ }^{\circledR}$ HydroCoil Detachables, TERUMO CLINICAL SUPPLY CO.,LTD. Kakamigahara, Japan: 6 $\mathrm{mm} / 20 \mathrm{~cm}^{*} 2,8 \mathrm{~mm} / 20 \mathrm{~cm}^{*} 2,12 \mathrm{~mm} / 20 \mathrm{~cm}^{*} 2,15 \mathrm{~mm} / 30$ $\mathrm{cm}^{*} 5$ ). Cardiac catheterization was completed without complications. About 4 hours after the catheterization, the patient complained of severe, dull, and smarting pain at the right dorsal region with radiation to the upper abdominal region. She had difficulty breathing and lying on the bed because of the severe back pain. The total scores of the McGill Pain Questionnaire (MPQ) ${ }^{3)}$ and Numerical Rating Scale (NRS) ${ }^{4)}$ were 20 and 10, respectively. Electrocardiography showed no significant ST-T change and the levels of creatine kinase-MB and cardiac troponin $\mathrm{T}$ were within their normal ranges. The patient had no past history of any psychiatric disorder. Loxoprofen sodium hydrate and diclofenac sodium were not effective for the pain relief. Pentazocine temporarily relieved the pain, but it continued with NRS of 6/10. Plain chest CT performed 3 days after the catheterization revealed no bleeding or pleural effusion. The size of the collateral after coil embolization became larger than that of the pre-treatment state (Figure 2A, B). A giant collateral was located right by the spinal column (Figure 2B). Blood chemistry showed mild CRP elevation of 2.3 $\mathrm{mg} / \mathrm{dL}$. We suspected the neuropathic and/or inflammatory pain was due to the compression of adjacent nerves by the giant collateral filled in coils. Hence, we started to use pregabalin (150 mg/day) and methylprednisolone (mPSL, $80 \mathrm{mg} /$ day) 4 and 7 days after catheterization, respectively, but the pain was not relieved at all (NRS was 6-7). The patient complained of feeling like an unidentified object was stuck in her stomach 7 days after the catheterization. Hence, we performed esophageal fluoroscopy on day 9 after the catheterization, the results of which suggested mild compression of the esophagus by the collateral in the coils (Figure 3A, B). The pain gradually became localized to the right dorsal region. Tramadol hydrochloride for the purpose of withdrawal of pentazocine was partly effective, but it was discontinued due to the onset of renal failure. We started carbamazepine (CBZ, $200 \mathrm{mg}$ /day) on day 15 after catheterization, which successfully relieved the intracta- 

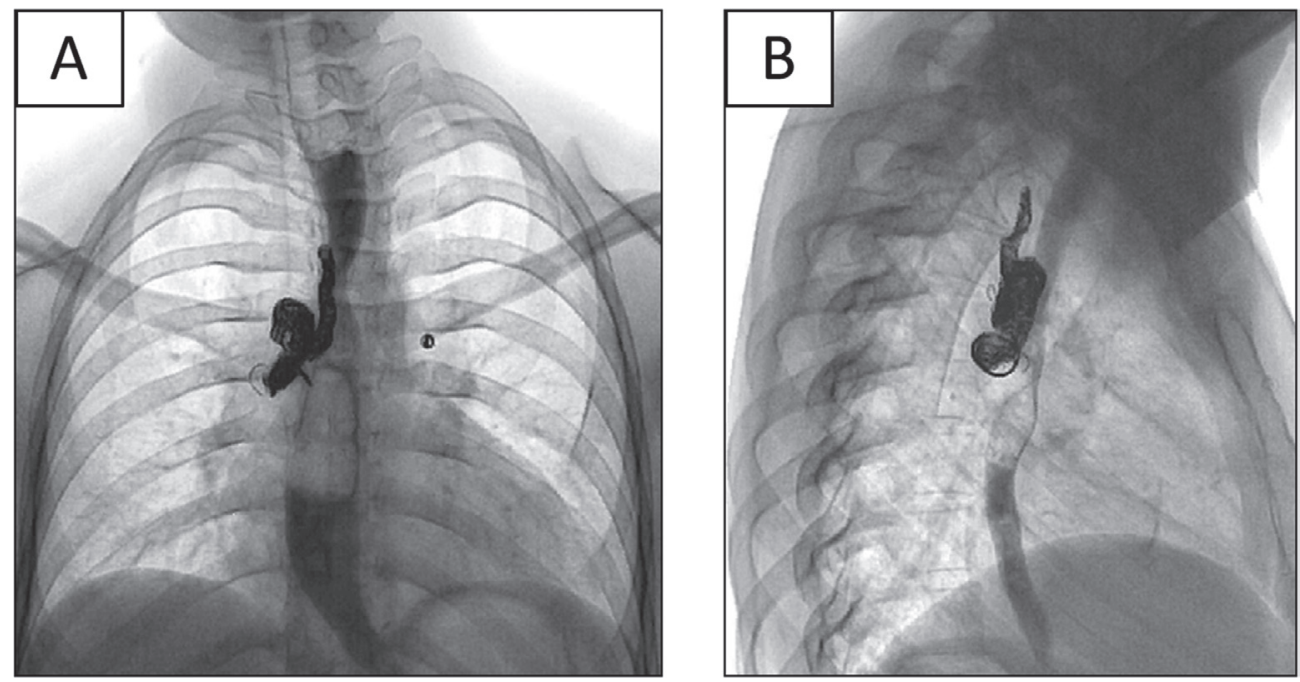

Figure 3. Esophageal fluoroscopy on day 9 after the catheterization. Esophagus seems to be mildly compressed by giant veno-venous collateral. A: Frontal view. B: Lateral view.

ble pain (NRS improved from 6 to 2). She was discharged from our hospital on day 16 after catheterization. CBZ was gradually tapered and completely stopped 4 months later. Serum cytokine (interleukin-2, 4, 6, and 10, tumor necrosis factor- $\alpha$, and interferon- $\gamma$ ) levels were not elevated before and after the use of mPSL, compared with the standard controls (data not shown).

\section{Discussion}

This is the first demonstration of an association between intractable back pain and coil embolization of veno-venous collaterals in patients with the Fontan procedure. A major concern is the pathogenesis of the pain in the present patient. Pain is often categorized as being either nociceptive or neuropathic. ${ }^{5}$ Nociceptive pain is the perception of nociceptive input, usually due to tissue damage (eg, postoperative pain). ${ }^{5}$ Nociceptive pain is classified into somatic and visceral pain. Somatic pain arises from injury to body tissues. It is well localized but variable in description and experience. ${ }^{5}$ Visceral pain originates from the viscera mediated by stretch receptors. ${ }^{5)}$ It is poorly localized, deep, dull, and cramping (eg, pain associated with appendicitis, cholecystitis, pleurisy, acute aortic dissection, or acute myocardial infarction). ${ }^{5)}$ The pharmacologic approach to nociceptive pain involves opioid analgesics, cyclooxygenase 2 (COX2) inhibitors, NSAIDs with a proton pump inhibitor, acetaminophen, and steroids. ${ }^{6,7)}$ Neuropathic pain arises from abnormal neural activity secondary to disease, injury, or dysfunction of the nervous system (eg, disk herniation, carpal canal syndrome, trigeminal neuralgia, or diabetic neuropathy). ${ }^{5}$ Opioid analgesics, antidepressants, anti-arrhythmic agents, or antiepileptic drugs may be used for the treatment of neuropathic pain.-9)

In the present case, the major painful site was the right dorsal region and consistent with that of the treated collaterals. We first thought the category of the present patient's pain might be vascular pain because the characteristics of the pain (pulsatile, dull, and worsened with breath) seemed to be that of visceral pain belonging to nociceptive pain rather than neuropathic pain. An enlarged diameter of the collateral after coil embolization due to the extensibility of coils and expansion of hydrogel coating, might stimulate the stretch receptors, located in the outer membrane of large arteries and veins. ${ }^{5,6}$ However, the poor efficacy of non-steroidal anti-inflammatory drugs (NSAIDs) and steroids, and the preferable effect of CBZ suggested that this condition occurred as neuropathic rather than nociceptive pain. ${ }^{8,9)}$ No significant elevation of circulating proinflammatory cytokines indicated vascular inflammation and/or tissue destruction. Esophageal nerve plexus or nerves over the periosteum of the vertebra run close to the therapeutic region. The findings of esophageal fluoroscopy (Figure 3A, B) and CT (Figure 2B), or chest discomfort of the present patient suggest that the severe back pain might be neuropathic pain that was caused by the compression of these nerves by the enlarged collateral. The lack of elevation of deviation enzymes assessed by blood chemistry did not suggest unexpected embolization. ${ }^{1)}$ Although a metallic allergy could cause chest discomfort, it was unlikely because she had neither a previous history of metallic allergy nor remission after steroid therapy. ${ }^{10)}$

Treatment-related pain is difficult to differentiate from critical embolization after coil embolization. The risk of vascular occlusion depends on the number of target collaterals (eg, artery/vein, location, size) as well as the neighboring structures (eg, esophagus, esophageal nerve plexus, nerves on the periosteum). The bigger the volume of the target collateral after embolization is, the higher the risk of being stretched for the collateral and compression of neighboring structures might be. Amplatzer vascular plug ${ }^{\circledR}$ may control the complication in patients with the Fontan procedure because of the reduction of the required number of coils. ${ }^{1,11)}$ Neuralgia is one of the differential diagnoses of treatment-related pain after coil embolization for veno-venous collaterals in patients with Fontan circulation. 


\section{ACKNOWLEDGMENTS}

We thank Ms. Midori Wakabayashi-Takahara of the Department of Pediatrics, Yamaguchi University Graduate School of Medicine for the cytokine assay.

\section{REFERENCES}

1. Mullins CE. Occlusion of abnormal small vessels, persistent shunts, vascular fistulae including perivalvular leaks. In: Mullins CE, eds. Cardiac Catheterization in Congenital Heart Disease: Pediatric and Adult. 1st ed. Malden, MA: Blackwell Publishing, Inc.; 2006: 661-92.

2. Ono Y, Mitsushita N. Case studies of patients successfully and unsuccessfully managed pre- and post-Fontan procedure. Int Heart J 2015; 56: S31-4.

3. Melzack R. The McGill Pain Questionnaire: major properties and scoring methods. Pain 1975; 1: 277-99.

4. Hjermstad MJ, Fayers PM, Haugen DF, et al; European Palliative Care Research Collaborative (EPCRC). Studies comparing $\mathrm{Nu}$ merical Rating Scales, Verbal Rating Scales, and Visual Analogue Scales for assessment of pain intensity in adults: a systematic literature review. J Pain Symptom Manage 2011; 41: 1073-93. (Review)
5. Rosenquist EW. Definition and pathogenesis of chronic pain. UpToDate 2016. Available at: http://www.uptodate.com/contents/ definition-and-pathogenesis-of-chronic-pain? Accessed January 27, 2017.

6. Swieboda P, Filip R, Prystupa A, Drozd M. Assessment of pain: types, mechanism and treatment. Ann Agric Environ Med 2013; 1: 2-7. (Review)

7. Yaksh TL, Woller SA, Ramachandran R, Sorkin LS. The search for novel analgesics: targets and mechanisms. F1000Prime Rep 2015; 7: 56. (Review)

8. Mendlik MT, Uritsky TJ. Treatment of Neuropathic Pain. Curr Treat Options Neurol 2015; 17: 50

9. Wiffen PJ, Derry S, Moore RA, Kalso EA. Carbamazepine for chronic neuropathic pain and fibromyalgia in adults. Cochrane Database Syst Rev 2014; 4: CD005451.

10. Wertman B, Azarbal B, Riedl M, Tobis J. Adverse events associated with nickel allergy in patients undergoing percutaneous atrial septal defect or patent foramen ovale closure. J Am Coll Cardiol 2006; 47: 1226-7.

11. Tang L, Fang ZF, Zhou SH. Vessel embolization: Transcatheter embolization of pulmonary arteriovenous malformations and aortopulmonary collateral arteries. In: Butera G, Chessa M, Eicken A, Thomson J, eds. Cardiac Catheterization for Congenital Heart Disease: From Fetal Life to Adulthood. Milan, Italy: Springer Verlag Italia; 2015: 527-48. 